\title{
TRANSLATION ERRORS IN THE PROCESS OF TRANSLATION
}

\author{
Kartini Rahmatillah
}

STIE Madani Balikpapan

\begin{abstract}
Translation nowadays is noted as a kind of skill of transferring messages from one language into another language. One cannot translate something without ignoring errors that may happen during the process of translation. These errors are not ignorable since translation deals with how to bring the same message from one language and to make these messages into the same meaning in other language. Form may differ but the message itself cannot be changed.

Since this paper is not a result of a research, it is only intended to enlighten translation errors that may occur during the translation process. Some errors are familiar but others may not to some translator due to different cultural background. Regarding to these errors, there are also solution on how to overcome these errors. Though this paper is not a scientific research but still there are information that may be used for translator, especially those who always face these similar errors. In the end, it can be concluded that how expert a translator is, he or she cannot ignore and may face the errors, and it becomes a tricky problem for translators.
\end{abstract}

Keywords: transalation process, errors

\section{INTRODUCTION}

In the present era of globalization, translation plays a major role in conveying messages from one language to another. However, translation is not an easy task as we can witness many cases of wrong translations. In the process of translation, either from Indonesian to any foreign languages or from any foreign languages to Indonesian, translators cannot ignore the errors which can happen 
during the translation. These errors often happen and must be overcome by translators.

Translation is similar with communication in a way that we transfer information from the sender to the receiver in written texts. In this process there are at least two factors involved, one is the sender or the one who wants to send the message to someone else, second is the receiver or the one who will receive the message. The problem is that the sender send message through language that the receiver do not understand. That is why they both need someone who can help them to translate the language so that the message will be understood by the receiver. This person is called a translator and acted as a mediator between the sender and the receiver. Before we come to the full explanation about errors in translation, let us take a look first to the history of translation.

The study of translation emerged as a new academic field during the twentieth century, focusing particularly on the past thirty years (Venuti, 2000; 1). On that era, translation focused mainly to the literary works and Bible. For the literary works, the poets from all over the world tried to expose their works so that everyone would know their works. But the problem was that not everyone understands the languages. They need someone who can help them compose the works in languages that they understand. From here then translation field emerged. So did the Bible translation.

Translation had previously been regarded as an art or a craft; now the translation scholars were happy to have their activity recognized as a science and admitted to the inner circle of scholarly pursuits as a branch of applied linguistics (Nord, 1997; 10). What exactly is the definition of translation? Catford $(1965 ; 20)$ defined translation as the replacement of material in one language (Source Language) by equivalent material in another language (Target Language). While Nida and Taber (in Nord 1997; 7) said that translating consists in reproducing in the receptor language the closest natural equivalent of the source-language message. From these definitions we can conclude that there are at least two factors involved in translating, they are the sender or the Source language which will be translated and the receiver or the Target Language which translators must translate it into.

Having known what factors involved in translating, the question is what the function of translating is or why does people need translation? Basically the process of translating is the same as the process of communication in the way that we exchange or transfer something from the Source Language to the Target 
Language or from the Sender to the Receiver. The main difference is that in translating we do it in written form while in communication we do it orally. In translating the role of the translators are only as mediator or the one who know how to transfer information from the Source Language to the Target Language.

We already know so far that translators transfer information from one language to another language in order that people with different knowledge of a certain language will know the information. The question is that how can translators be successful in translating something? What is the main factor that they must follow in order that people with knowledge of different language from his can understand the information? The answer is that translators must overcome all problems which they will face during the translation process because translation is the matter of mixing two cultures, two perceptions, two languages and others into a one solid written material that will be understood by the receiver. Translators need something what is called a translational competence which according to Pym (1990) :

- The ability to generate a TT (target text) series of more than one viable term (TT1, TT2...TTn) for a ST (source text).

- The ability to select only one TT from this series, quickly and with justified confidence, and to propose this TT as a replacement of ST for a specified purpose and reader.

Together, these two skills form a specifically translational competence to the extent that their union concerns translation and nothing but translation. They have little to do with strictly linguistic competence. There can be no doubt that translators need to know a good deal about grammar, rhetoric, terminology, world knowledge, common sense and strategies for getting paid correctly, but the specifically translational part of their practice is strictly neither linguistic, common nor commercial. It is a process of generation and selection between alternative texts.

The writer think that the title here is interesting to talk to since the writer think that most of translators ever meet some errors during their translation process. Not only translators who still begin their translation but also professional translators sometimes still face these errors. How can these errors occur and how to overcome these errors? Here the writer will explain about these errors and hope with this paper all translators including the writer herself will finally can overcome or at least reduce the errors that occur in the translating process. 
Errors in translation mostly result from the non-equivalence between the source and target languages (Baker : 1992). However, good translators with encyclopedic knowledge and linguistic knowledge of both the source and target languages know how to deal with them; therefore, errors can indicate the quality of a translation; moreover, they can reveal what is going on in the translator's thinking process (Seguinot : 1990). Translation errors according to Sigrid Kupsch-Losereit in Nord (1997: 73) as an offence against: 1. the function of the translation, 2. The coherence of the text, 3 . The text type or text form, 4. linguistic conventions, 5 . Culture- and situation-specific conventions and conditions, and 6. the language system. While Wilss (1982) describes a translation error as an offence against a norm in a linguistic contact situation. From these definitions about translation errors, we can conclude that there are many aspects involved in translating, not only how to translate the text meaningful but also translators must pay attention to the context related to the culture and conditions that the text can be applied. It is not a simple task to do for translators. If the expression or the text is hard to understand even to translators themselves, the function of translation then fails to fulfill.

Experience shows that students make fewer linguistic mistakes if they have an exact idea of the situation for which they are translating (Nord, 1997; 74). So must translators. They must first know the conditions of how they translate something. If translators cannot imagine who is addressing whom and for what purpose, they will cling to the source-text surface structures for fear of missing the goal of translating (Nord, 1997; 74). If translators miss the goal of translating then the translation will be defined as "bad translation".

Errors in translation are usually interrelated to each other. It means that one error or problem influence other errors. So does the solution. Because the errors are connected, the ways to overcome for one error will influence the solutions for other errors. It is like there are networks or hierarchies in which the solution to one problem influences the way others are tackled (Nord, 1997; 75).

\section{THE CLASSIFICATION OF TRANSLATION ERRORS}

If a translation error is defined as a failure to carry out the instructions implied in the translation brief and as inadequate solutions to a translation problem, then translation errors can be classified into four categories (Nord, 1997; 75):

V Pragmatic translation errors, caused by inadequate solutions to pragmatic translation problems such as a lack of receiver orientations 
v Cultural translation errors, due to an inadequate decision with regard to reproduction or adaptation of culture-specific conventions

v Linguistics translations errors, caused by an inadequate translation when the focus is on language structures

$v$ Text-specific translation errors, which are related to a text-specific translation problem and, like the corresponding translation problems, can usually be evaluated from a functional or pragmatic point of view.

After we know the classification of translation errors, then we know what exactly the main translation errors that mainly happen or face by translators. Now we will explain these errors one by one and the solutions for these errors according to a top-down hierarchy.

The main problem with the pragmatic translation errors lies in that the receivers tend to not to realize they are getting wrong information. This problem is among the most important a translator can make. This is because the first decision in the translation process refers to the translation type best suited to the translation purpose, and each following step will be guided by this decision. Once translators make these pragmatic errors, the whole process of translation is nothing. The way they can overcome this errors is only by asking someone with a translational competence comparing the source and target text in the light of the translation brief (Nord, 1997; 76).

If the purpose of the translation task is to test language proficiency (as in foreign-language classes), linguistic errors will perhaps carry more weight than cultural errors. If the purpose of the translation task is to test cultural proficiency, cultural translation problems could even be ranked higher than pragmatic errors. The grading of cultural translation errors and linguistic translation errors depend on the influence they have on the function of the target text. If a missing comma or a spelling mistake leads to an inadequate interpretation of the referential function, the error is no longer a mere deviation from linguistic norms. Linguistic errors are often due to deficiencies in the translator's source or target-language competence (Nord, 1997; 76). The conclusion we can make from these two errors is that once someone starts to choose a translator as his profession, one thing he must acquire first is an adequate level of language and culture proficiency. If they fail to have this element, translating will then become no more than an instrument for foreignlanguage learning, with the focus on linguistic correctness rather than communicative or functional appropriateness (Nord, 1997; 78). 
One of the major and foremost components in the translating process is the fact that the translator has to read the original and interpret it in the target language. A fledgling translator may make errors at this stage due to his/her weak reading process. According to Suksaeresup and Tipa Thep-Ackrapong (2009) errors found at this stage can be divided into the following categories:

\section{Miscue}

Miscue is a term coined by Goodman (1969) referring to an incorrect guess made by a reader when reading a text. For example, the word program is read as performance; ready as reading, county as country and so forth. Usually beginner readers make a lot of miscue errors; however, when their reading improves, they tend to make fewer of this type of errors. In translation, some students with poor reading skills transfer the miscues into their translated text. For example, in an assignment, years ago, one of us was surprised by the fact that many students made the same error in translating the following.

\section{The translator's wrong assumption of the background knowledge}

The following case shows how a translator's miscues and his/her strong assumption of the background knowledge can affect the translation.

In the 1970s, the pace of communication was slower than today's. When the Academy of Motion Picture Arts and Sciences announced the movies nominated for awards, they sent in the movie titles to newspapers around the world. Many years later probably in the early 1980s, a hilarious anecdote appeared in a Thai newspaper recounting the translation of two movie titles: Kramer vs Kramer (1979) and The Deer Hunter (1978). In the first case, it was translated in Thai as Khmer fighting Khmer and in the second as Hunting a Derogatory Title Liar. Obviously, the translation was a far cry from its original meaning. Probably the translator made a miscue of the name Kramer as Khmer because he/she was influenced by the raging war in Cambodia (1975-1979) during that period of time. In the second translation, the deer was miscued as dear, a term of endearment often used by American GIs to Thai lovers during their furloughs during the Vietnam War. Probably, the translator assumed that the movie was about an American soldier in the Vietnam War hunting for a girlfriend, or someone termed as a dear. The movie was made in 1978, shortly after the end of the Vietnam War (1965-1975). Therefore, the translator may have been influenced by the war events in his/her translation. 
From the discussion, it is suggested that a competent translator should have an inquisitive mind constantly searching for encyclopedic knowledge (Hatim \& Mason, 1990, pp 106-107) so that he/she can acquire appropriate background knowledge to interpret the source language text without incorring in embarrassing errors.

\section{Errors in propositional meaning}

The propositional meaning refers to the relationship between a word and what it refers to or describes as conceived by the speakers as true or false (Baker, 1992). Errors in this category can further be divided into the following:

Wrong alternate meaning of a word

Some fledging translators select a wrong alternate meaning of a word. For example, the word right can be translated as right as opposed to wrong and right as opposed to left. In the following example, the translator translates the word as opposed to left, but in fact, it should have been the other meaning.

The above examples show the translator's problem in using the dictionary. Probably, he/she hurriedly selects the first definition of a word without considering the possibility of another alternate meaning which would better fit the context. To address the problem, translators should be trained in the use of dictionaries. However, the use of a dictionary alone is not recommended because it is boring. In fact, it should be done to aid the reading process. By this means, the translators will learn how to read and at the same time how to use a dictionary efficiently.

\section{Errors in translating expressive meaning}

Another aspect of lexical meaning is expressive meaning. Baker (1992) defines expressive meaning as a word that cannot be evaluated as true or false because the word in question has to do with the speaker's feeling and experience For example, the word dog in English has a good connotation because dogs in the English-speaking context are considered humans' loyal friends. In contrast, in Thai, the word $\operatorname{dog}$ is considered derogatory because they always fight among themselves and scavenge for food.

Therefore, expressive meaning can pose many problems for translators, especially fledgling ones. In the following discussion, errors in this respect are further classified into wrong translation of idiomatic expressions and of terms of address. 
a. Translating idiomatic expressions after their propositional meaning English has a great number of idiomatic expressions. A translator who is not familiar with these expressions tend to take them for their propositional meanings.

For example: Original text : The sports car is cool.

Back-translated text: The sports car is temperature-wise cool.

To address the problem of misinterpreting idiomatic expressions, again, the translators are recommended to read and write in English extensively. However, not all genres contain idiomatic expressions. Fiction such as novels, plays, TV series and movies usually has a lot of idioms. Entertainment such as songs and computer games also does. These genres certainly will familiarize the translators with a great variety of idiomatic expressions. However, idiomatic expressions are short-lived. For example, the slang word fresh, which is similar to the today's slang cool, was widely used in Hollywood movies in the 60's. However, the word is no longer known to today's young people in that meaning. Therefore, a competent translator has to constantly keep up with new idioms.

b. Translating terms of address after their propositional meanings

In some cases, terms of address are wrongly translated.

For example: Original text : Good morning, honey.

Back-translated text: Good morning, Ms Honey.

The word honey is meant to be a term of endearment, but it is translated as woman's name.

\section{CONCLUSION}

So far, some translation errors are already discussed here with some examples that merely could happen and faced by the translators. What can be concluded from these usual errors is that these errors happens because of lack of reading, either of the target text or any source of reading materials, because once translator has lack of reading, it will be impossible to translate the exact material in the target text. Also the way of using dictionary is a point that translator must have. Using dictionary does not mean that translator must translate word by word by seeing from the dictionary, because it will spend much time only by looking to the 
word being translated. Using the wise way of dictionary is the one that translator must achieve. Translator must gain and always acquire encyclopedic knowledge so that they will expand their knowledge not only in one subject, but also in different subjects, like knowledge in music, novels, politics, economic. This will help them in their process of translating.

Thus, one believes in the necessity that translation deserves importance and we should not consider it a mechanical process that can be done with the help of a dictionary. It is a much more complex and interesting activity, that does not involve only a simple linking of words. The idea that language is dependent on dictionaries and grammars is completely wrong. A good translator must have this in his head and he should also have much more information than any dictionary or grammar can provide, his aim being that of producing a clear and pleasant text.

Translation itself, if can be summarized that it is a process of "transfer or meaning" from one language to another language. From this theory we have to bear in mind that it is impossible to have exactly the same meaning although we try hard to present them in our translation. As what is said by Sapir (in Basnett: 1980) that no two languages are ever sufficiently similar to be considered as representing the same social reality. The worlds in which different societies live are distinct worlds, not merely the same world with different labels attached. No one can ever translate something in one language to another language without changing the word to make it equivalent with the source text. Because translation does not merely about how to change the words in source text and replace them with the word in target text with the similar meaning.

In his article 'On Linguistic Aspects of Translation', Roman Jakobson (1959) distinguishes three types of translation:

(1) Intralingual translation, or rewording (an interpretation of verbal signs by means of other signs in the same language).

(2) Interlingual translation or translation proper (an interpretation of verbal signs by means of some other language).

(3) Intersemiotic translation or transmutation (an interpretation of verbal signs by means of signs of nonverbal sign systems).

Having established these three types, of which (2) translation proper describes the process of transfer from SL to TL, Jakobson goes on immediately to point to the central problem in all types: that while messages may serve as adequate 
interpretations of code units or messages, there is ordinarily no full equivalence through translation. Even apparent synonymy does not yield equivalence, and Jakobson shows how intralingual translation often has to resort to a combination of code units in order to fully interpret the meaning of a single unit. Hence a dictionary of so-called synonyms may give perfect as a synonym for ideal or vehicle as a synonym for conveyance but in neither case can there be said to be complete equivalence, since each unit contains within itself a set of non-transferable associations and connotations.

Translation is a process of converting one language ( $\mathrm{SL}=$ Source Language) to another ( $\mathrm{TL}=$ Target Language) so that the TL could convey the intended message in SL. In other words, it is a process through which the translator decodes SL and encodes his understanding of the TL form. It is worth mentioning, however, it is not meant that the translator should always find one-to-one categorically or structurally equivalent units in the two languages, that is, sometimes two different linguistic units in different languages carry the same function.

There is, after all, no reason to fear translation errors in the teaching situation. There is no overriding reason to insist on perfect linguistic competence or extensive text analysis before getting down to translating, since errors are going to be made, and the best way to learn is often to start making them. We all fall into error. We cannot avoid errors in every translation process because errors are usually exist during the translation process. As translators we must to overcome these errors, not to run away from these. Errors are going to be made during the process of translation, so our task as translator to get rid of the errors and try hard to present the target text as equivalent as the source text.

\section{REFERENCES}

Baker, M. 1992. In other words: A Coursebook on Translation. London and New York : Routledge.

Catford, John Cunnison. 1965. A Linguistic Theory of Translation: An Essay in Applied Linguistics. London: Oxford University Press.

Goodman, K. S. 1969. Analysis of oral reading miscues: Applied psycholinguistics. Reading Research Quarterly.

Hatim, B. \& Mason, I. 1990. Discourse and the translator. London and New York: Longman. 
Karimi, Lotfollah. Equivalence in Translation. Volume 10, No. 1 January 2006 accurapid.com/journal.

Roman Jakobson. 1959. On Linguistic Aspects of Translation. in R.A. Brower (ed.), On Translation (Cambridge, Mass.: Harvard University Press.

Nord, C. 1997. Text Analysis in Translation: Theory, Methodology and Didactic Application of a Model for Translation-Oriented Text Analysis. Amsterdam : Rodopi.

Pym, Anthony. 1990. "A Definition of Translational Competence, Applied to the Teaching of Translation". Paper presented to the 12th World Congress of the FIT, Belgrade.

Seguinot, C. (1990). Interpreting errors in translation. Meta, 35,pg 68.

Suksaeresup, Nitaya and Tipa Thep-Ackrapong. Lost in Translation : Volume 13, No. 1 January 2009 Translation Journal and the Author.

Venuti, Lawrence (ed.) 2000. Translation Stiudies Reader. London and New York: Routledge.

Wills, W. 1982. The Science of Translation : Problems and Methods. Tubingen: Gunter. 